\title{
Free Vibration of Functionally Graded Rayleigh Beam
}

\author{
Mehmet Avcar $^{a *}$, Hiyam Hazim AlSaid Alwan ${ }^{b}$ \\ ${ }^{a}$ Department of Civil Engineering, Faculty of Engineering, Suleyman Demirel University, Cunur, Isparta, Turkey \\ ${ }^{b}$ Graduate School of Natural and Applied Sciences, Suleyman Demirel University, Cunur, Isparta, Turkey \\ *E-mail address: mehmetavcar@yahoo.com
}

Received date: June 2017

Accepted Date: July 2017

\begin{abstract}
In the present study, free vibration of Rayleigh beam composed of functionally graded materials (FGMs) is investigated. For this purpose, the equation of the motion of functionally graded (FG) beam derived according to Rayleigh beam theory. The material properties are assumed to vary continuously through the thickness of the beam according to the power-law form. Resulting equations are solved for simply supported boundary conditions. In order to validate the results, a comparison is carried out with available results for homogeneous beam. The effects of varying material properties on the dimensionless free vibration frequency parameters are examined. It is seen that varying material properties have significant effects on dimensionless free vibration frequency parameters of FG Rayleigh beam
\end{abstract}

Keywords: Beam, Free Vibration, Rayleigh beam theory, Functionally Graded Materials (FGMs).

\section{Introduction}

FGMs are extensively used in machinery, space, nuclear and civil engineering; high temperature exposed building components, space vehicles, microelectronics, and industrial applications. These types of materials were first introduced by Japanese scientists in 1984 as thermal barrier materials. FGM is typically a mixture of a ceramic and a metal so that the metal can withstand high temperatures in the thermal environment as well as reduce the tensile stresses that would otherwise occur on the ceramic surface during the first stages of cooling [1-4].

Beam structures have large applications in engineering field and studying the vibration behavior of this kind of structural components are important for understanding the behavior of more complex and real structures subjected similar conditions. Therefore, researchers have been focused on the vibration analysis of beam structures using different theories and several solution methods [5-13].

Due to the advantages and increasing use of FGMs and importance of the beam structures in the engineering field, many studies have been performed on the vibration problems of FG beams [14-22]. 
From the search of open literature, it is seen although there are numerous studies on the vibration analysis of FG beams using different beam theories, the number of works depending on Rayleigh beam theory is still limited. An attempt is made to address this problem. For this purpose, the equation of the motion of FG beam derived using Rayleigh beam theory. The functionally graded material properties are assumed to vary continuously through the thickness direction of the beam according to power law form. Resulting equations are solved for simply supported boundary conditions. In order to validate the results, a comparison is carried out with available results for homogeneous beam. The effects of varying material properties on the dimensionless free vibration frequency parameters are examined.

\section{Effective material properties of FGMs}

Consider a FGM beam consist of ceramic-metal, which has length, L, width b, and thickness, h, as shown in Fig. 1.

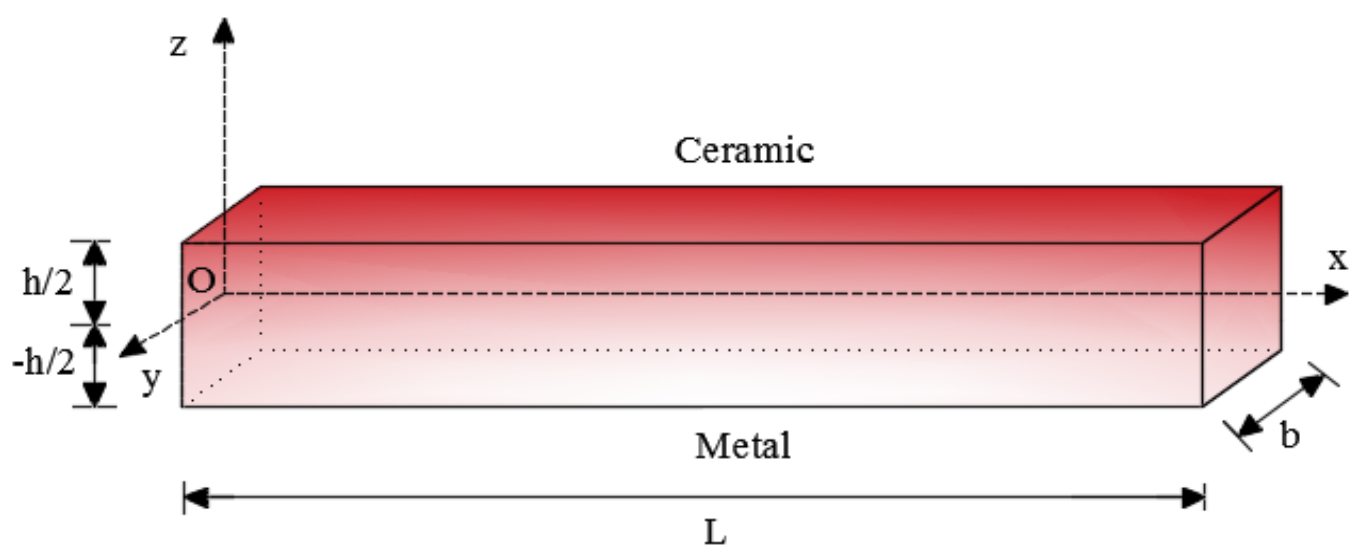

Fig. 1. Geometry of a functionally graded beam

The effective material properties of the FG beam, i.e., Young's modulus E and mass density $\rho$, vary continuously through the thickness direction according to a function of the volume fractions of the constituents while Poisson's ratio $v$ is taken to be constant.

According to the rule of mixture, the effective material properties, $\mathrm{P}$, can be expressed as

$$
\mathrm{P}=\mathrm{P}_{\mathrm{m}} \mathrm{V}_{\mathrm{m}}+\mathrm{P}_{\mathrm{c}} \mathrm{V}_{\mathrm{c}}
$$

where $\mathrm{P}_{\mathrm{m}}, \mathrm{P}_{\mathrm{c}}, \mathrm{V}_{\mathrm{m}}$ and $\mathrm{V}_{\mathrm{c}}$ are the material properties and the volume fractions of the metal and the ceramic constituents respectively.

The total volume fraction of the metal and ceramic as follows 


$$
\mathrm{V}_{\mathrm{m}}+\mathrm{V}_{\mathrm{c}}=1
$$

The power law of volume fraction of the ceramic constituent of the beam as follows

$$
\mathrm{V}_{\mathrm{c}}=\left(\frac{\mathrm{z}}{\mathrm{h}}+\frac{1}{2}\right)^{\mathrm{d}}
$$

where $\mathrm{d}$ is a non-negative number $(0 \leq \mathrm{d} \leq \infty)$ called power law or volume fraction index, and $\mathrm{z}$ is the distance from the mid-plane of the beam. Note that, FG beam becomes a fully ceramic one as $d=0$ while it becomes a fully metallic one as $\mathrm{d}=\infty$.

The variation of the volume fraction of the ceramic constituent, $\mathrm{V}_{\mathrm{c}}$, through the thickness direction of the FG beam versus various values of power law index, $d$, is illustrated in Fig. 2. It is clear that the $V_{c}$ changes rapidly near the bottom surface for $d<1$ while it changes rapidly near the top surface for $d>1$.

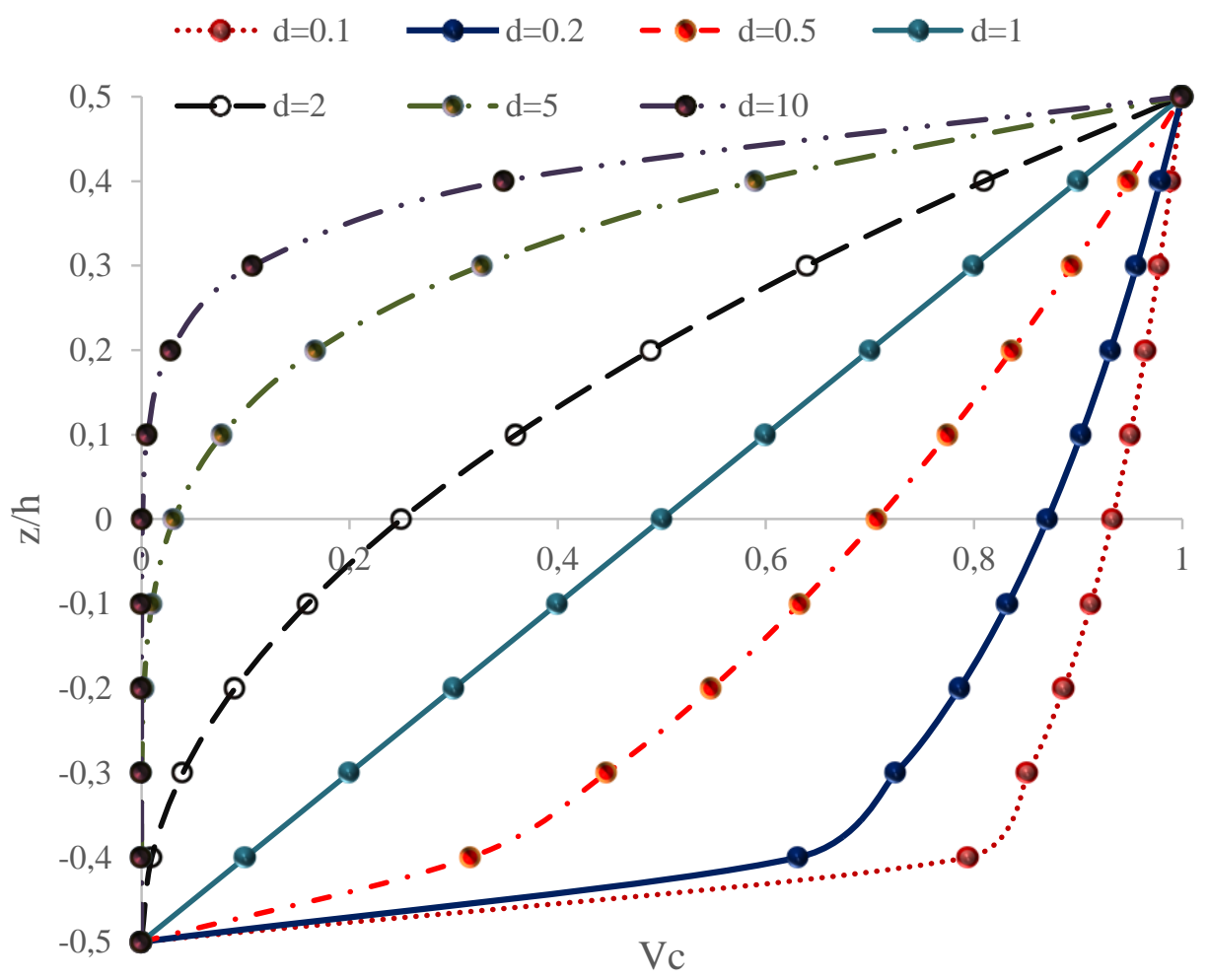

Fig. 2. Variation of volume fraction of the ceramic constituent along thickness of FG beam versus various values of power law index 


\section{Governing Equation}

Using Kirchoff-Love hypothesis, displacements at any point of a FG beam can be expressed as

$$
\begin{aligned}
& u(x, z, t)=u_{0}(x, t)+z \theta \\
& w(x, z, t)=w_{0}(x, t)
\end{aligned}
$$

where $\mathrm{u}_{0}(\mathrm{x}, \mathrm{t})$ and $\mathrm{w}_{0}(\mathrm{x}, \mathrm{t})$ are the displacements at mid-surface in the $\mathrm{x}$, and $\mathrm{z}$ directions, respectively, and $\theta$ is the rotation of the cross section at the mid-plane.

The normal strain and shear strain are

$$
\begin{gathered}
\varepsilon(x, z, t)=\frac{\partial u_{0}}{\partial x}+z \frac{\partial \theta}{\partial x} \\
\gamma_{x z}=\theta+\frac{\partial w_{0}}{\partial x}
\end{gathered}
$$

Rayleigh beam theory neglects the shear strain, $\gamma_{x z}=0$, hence we have

$$
\varepsilon(\mathrm{x}, \mathrm{z}, \mathrm{t})=\frac{\partial \mathrm{u}_{0}}{\partial \mathrm{x}}-\mathrm{z} \frac{\partial^{2} \mathrm{w}_{0}}{\partial \mathrm{x}^{2}}
$$

According to the Hooke's law, the normal stress is defined as

$$
\sigma(\mathrm{x}, \mathrm{z}, \mathrm{t})=\mathrm{E}(\mathrm{z}) \varepsilon=\mathrm{E}(\mathrm{z})\left(\frac{\partial \mathrm{u}_{0}}{\partial \mathrm{x}}-\mathrm{z} \frac{\partial^{2} \mathrm{w}_{0}}{\partial \mathrm{x}^{2}}\right)
$$

The stress resultants in terms of axial force, $N_{x}$, bending moment, $M_{x}$, and transverse shear force $Q_{x}$, can be written as 


$$
\begin{gathered}
N_{x}=\int_{A} \sigma_{x} d A=A_{1} \frac{\partial u_{0}}{\partial x}-B_{1} \frac{\partial^{2} w_{0}}{\partial x^{2}} \\
M_{x}=\int_{A} \sigma_{x} z d A=B_{1} \frac{\partial u_{0}}{\partial x}-D_{1} \frac{\partial^{2} w_{0}}{\partial x^{2}} \\
Q_{x}=\frac{\partial M_{x}}{\partial x}=B_{1} \frac{\partial^{2} u_{0}}{\partial x^{2}}-D_{1} \frac{\partial^{3} w_{0}}{\partial x^{3}}
\end{gathered}
$$

where $A_{1}, B_{1}$ and $D_{1}$ are the material stiffness components of FG beam and defined as follow

$$
\left(A_{1}, B_{1}, D_{1}\right)=\int_{-h / 2}^{h / 2} \frac{E(z)}{1-v^{2}}\left(1, z, z^{2}\right) d z
$$

Taking into account the axial and rotary inertias, using Hamilton's Principle and after some mathematical operations, the governing equation of FG Rayleigh beam is derived as follows

$$
\Lambda_{11} \frac{\partial^{4} \mathrm{w}_{0}}{\partial \mathrm{x}^{4}}+\mathrm{I}_{0} \frac{\partial^{2} \mathrm{w}_{0}}{\partial \mathrm{t}^{2}}-\Gamma_{11} \frac{\partial^{4} \mathrm{w}_{0}}{\partial \mathrm{x}^{2} \partial \mathrm{t}^{2}}=0
$$

where the following definitions apply

$$
\begin{aligned}
& \Lambda_{11}=\left(\mathrm{D}_{1}-\frac{\mathrm{B}_{1}^{2}}{\mathrm{~A}_{1}}\right) \\
& \Gamma_{11}=\left(\mathrm{I}_{2}-\frac{\mathrm{I}_{1}^{2}}{\mathrm{I}_{0}}\right)
\end{aligned}
$$

here $\mathrm{I}_{0}, \mathrm{I}_{1}$ and $\mathrm{I}_{2}$ are the moment of inertia components of FG beam and defined as follow

$$
\left(I_{0}, I_{1}, I_{2}\right)=\int_{-h / 2}^{h / 2} \rho(z)\left(1, z, z^{2}\right) d z
$$




\section{Solution of Governing Equation}

FG Rayleigh beam is assumed to have simply supported boundary conditions in both ends. Hence, the following boundary conditions are satisfied:

$$
\begin{aligned}
& \mathrm{w}_{0}(0, \mathrm{t})=0, \quad \mathrm{w}_{0}(\mathrm{~L}, \mathrm{t})=0 \\
& \frac{\partial^{2} \mathrm{w}_{0}}{\partial \mathrm{x}^{2}}(0, \mathrm{t})=0, \quad \frac{\partial^{2} \mathrm{w}_{0}}{\partial \mathrm{x}^{2}}(\mathrm{~L}, \mathrm{t})=0
\end{aligned}
$$

Governing Eq.(13) can be rearranged as follows:

$$
\mathrm{a}^{2} \frac{\partial^{4} \mathrm{w}_{0}}{\partial \mathrm{x}^{4}}+\frac{\partial^{2} \mathrm{w}_{0}}{\partial \mathrm{t}^{2}}-\mathrm{b}^{2} \frac{\partial^{4} \mathrm{w}_{0}}{\partial \mathrm{x}^{2} \partial \mathrm{t}^{2}}=0
$$

where the following parameters applied

$$
\mathrm{a}^{2}=\frac{\Lambda_{11}}{\mathrm{I}_{0}} ; \mathrm{b}^{2}=\frac{\Gamma_{11}}{\mathrm{I}_{0}}
$$

The solution of Eq. (18) satisfying the boundary conditions (17) is assumed as [23]:

$$
w(x, t)=C \sin \frac{n \pi x}{L} \cos \omega_{n} t
$$

Substituting the Eq.(20) into Eq. (18) yields

$$
\mathrm{a}^{2}\left(\frac{\mathrm{n} \pi}{\mathrm{L}}\right)^{4}-\omega^{2}\left[1+\mathrm{b}^{2}\left(\frac{\mathrm{n} \pi}{\mathrm{L}}\right)^{2}\right]=0
$$

Finally, the formula for free vibration frequency of FG Rayleigh beam is obtained as follows 


$$
\omega=\sqrt{\frac{a^{2}\left(\frac{n \pi}{L}\right)^{4}}{\left(1+b^{2}\left(\frac{n \pi}{L}\right)^{2}\right)}}, \quad n=1,2, \ldots
$$

\section{Numerical Results}

In this section examples are given to examine the present problem. At first, a comparison has been performed to show the accuracy of the present formulation. Then, an example is exhibited to show the effect of power law index on the dimensionless free vibration frequency parameters of FG Rayleigh beam.

\subsection{Comparison Study}

To confirm the formulation given in Eq. (22), the values of natural frequencies of homogeneous beam, $\omega(\mathrm{rad} / \mathrm{sn})$, are compared with results of Rao [23] in Table 1. Here the following beam characteristics and material properties are taken into account:

$$
\begin{aligned}
& \mathrm{L}=1 \mathrm{~m}, \mathrm{~b}=0.05 \mathrm{~m}, \mathrm{~h}=0.15 \mathrm{~m}, \\
& \mathrm{~d}=0, \\
& E=207 \times 10^{9} \mathrm{~Pa}, \rho=76.5 \times 10^{3} \mathrm{~N} / \mathrm{m}^{3}
\end{aligned}
$$

Table 1. Comparison of the values of natural frequencies of homogeneous beam with results of Rao [23]

\begin{tabular}{llll}
\hline \multirow{2}{*}{ Source } & \multicolumn{3}{c}{$\omega(\mathrm{rad} / \mathrm{sn})$} \\
\cline { 2 - 4 } & $\mathrm{n}=1$ & $\mathrm{n}=2$ & $\mathrm{n}=3$ \\
\hline Present Study & 696.5834 & 2713.3651 & 5857.9512 \\
Rao [23] & 696.5987 & 2713.4221 & 5858.0654 \\
\hline
\end{tabular}

As it is seen in Table 1, the results are in good agreement and so the accuracy of the formulation is validated. 


\subsection{Illustrative example}

Fig. 3 shows the variation of dimensionless free vibration frequency parameters of FG Rayleigh beam, $\varpi$, for the first three modes versus power law index, d. Here, FG Rayleigh beam is assumed to be composed of Alumina $\left(\mathrm{Al}_{2} \mathrm{O}_{3}\right)$, and Aluminum (Al). Hence, the following beam characteristics and material properties are considered:

$$
\begin{aligned}
& \mathrm{L} / \mathrm{h}=5 \\
& \mathrm{E}_{\mathrm{c}}=380 \mathrm{GPa} ; \rho_{\mathrm{c}}=3960 \mathrm{~kg} / \mathrm{m}^{3} \\
& \mathrm{E}_{\mathrm{m}}=70 \mathrm{GPa} ; \rho_{\mathrm{m}}=2702 \mathrm{~kg} / \mathrm{m}^{3}
\end{aligned}
$$

The dimensionless free vibration frequency parameter of Rayleigh beam is defined as follow:

$$
\varpi=\frac{\omega L^{2}}{h} \sqrt{\frac{\rho_{m}}{E_{m}}}
$$

It is obvious from Fig. 3 that, the highest dimensionless free vibration frequency parameters are found for $\mathrm{Al}_{2} \mathrm{O}_{3}$ while the lowest ones are found for Al. Furthermore, dimensionless free vibration frequency parameters decrease with increasing power law index, $\mathrm{d}$. As a result, it is concluded that the dimensionless free vibration frequency parameters decrease as the material property of FG Rayleigh beam varies from ceramic to metal component. 


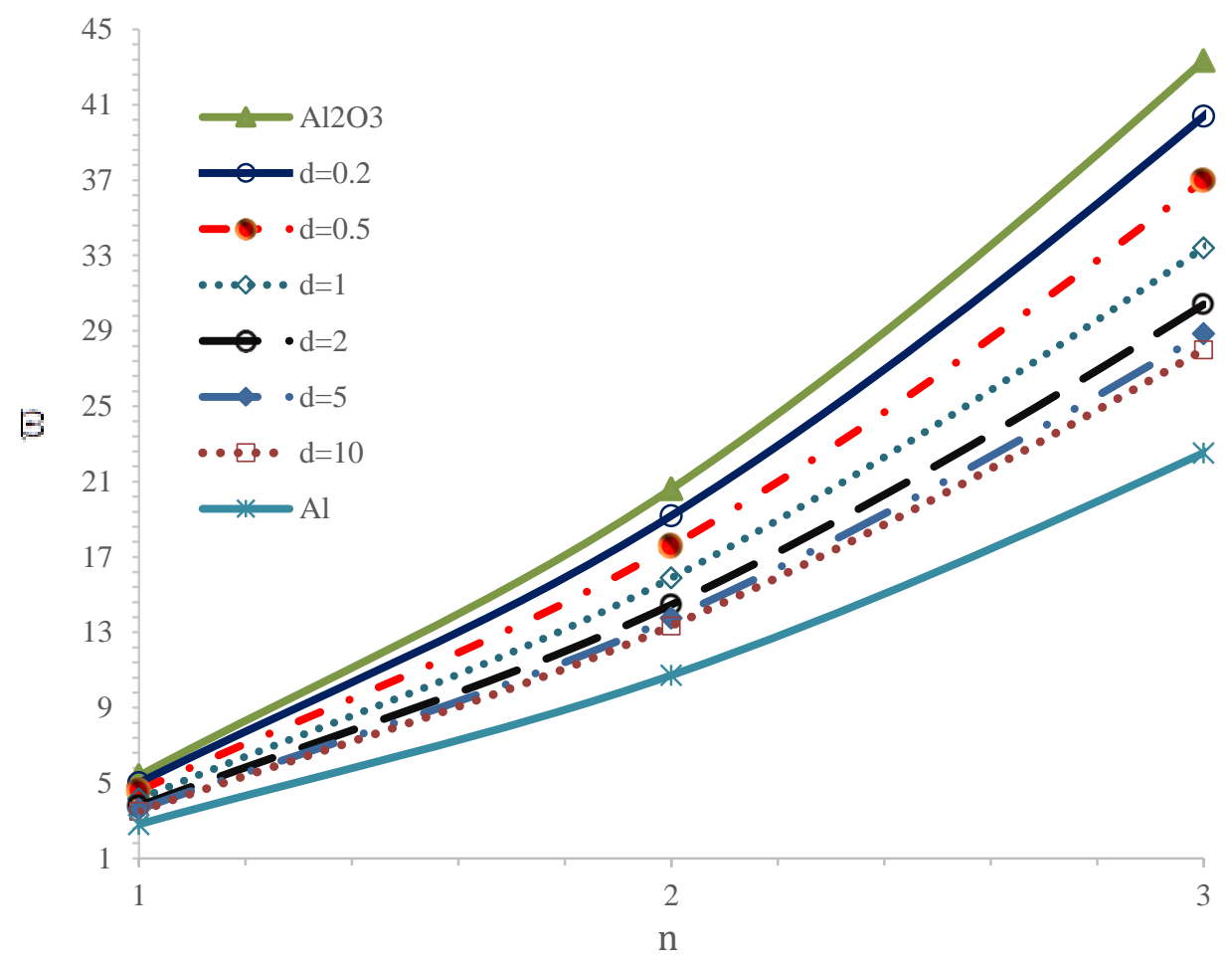

Fig. 3. Variation of dimensionless frequency parameters of FG Rayleigh beam versus power law index, $\mathrm{d}$.

\section{Conclusions}

In the present study the free vibration of the beam composed of FGMs is investigated using Rayleigh beam theory. The material properties are assumed to vary continuously through the thickness direction of the beam according to the power-law form. Resulting equations are solved considering simply supported boundary conditions. In order to validate the results, a comparison is carried out with available results for homogeneous beam. It is seen that varying material properties have significant effects on dimensionless free vibration frequency parameters of FG Rayleigh beam. Present analysis can be served as a comparative study or data for the different solution methods of future works.

\section{Acknowledgments}

The financial support of the Suleyman Demirel University Scientific Research Projects Unit (SDU-BAP) with Grand No. 4857-YL1-17 is gratefully acknowledged. The authors would like to thank institution. 


\section{References}

[1] Wakashima K., Hirano T., Niino M.. Space applications of advanced structural materials. ESA SP30397, 1990

[2] Koizumi, M., The concept of FGM. Ceramic Transactions, Functionally Gradient Materials, vol. 34, pp. 3-10, 1993.

[3] Suresh, S., Mortensen, A.,. Fundamentals of Functionally Graded Materials. IOM Communications, London, 1998.

[4] Kieback, B., Neubrand, A., Riedel, H., Processing Technique for Functionally Graded Materials. Materials Science and Engineering A, 362 , 81- 105, 2003.

[5] Han, M.S., Benaroya, H., Wei, T., Dynamics of transversely vibrating beams using four engineering theories. Journal Sound and Vibration, 225, 935-988. 1999.

[6] Civalek, O., Kiracioglu, O., Free vibration analysis of Timoshenko beams by DSC method. International Journal of Numerical Methods in Biomedical Engineering, 26, 1890-1898, 2010.

[7] Carrera, E., Giunta, G. and Petrolo, M., Beam Structures: Classical and Advanced Theories. John Wiley and Sons Ltd, 2011.

[8] Coşkun, S.B., Öztürk, B., Atay, M.T., Transverse Vibration Analysis of Euler-Bernoulli Beams Using Analytical Approximate Techniques. INTECH Open Access Publisher, 2011.

[9] Li, X.F., Tang, A.Y., Xi, L.Y., Vibration of a Rayleigh cantilever beam with axial force and tip mass. Journal of Constructional Steel Research,80, 15-22, 2013.

[10] Avcar M., Free Vibration analysis of beams considering different geometric characteristics and boundary conditions. International Journal of Mechanics and Applications, 4, 94-100, 2014.

[11] Avcar, M., Effects of rotary inertia shear deformation and non-homogeneity on frequencies of beam. Structural Engineering and Mechanics,55, 871-884. 2015.

[12] Arıbaş, Ü.N., Eratlı, N., Omurtag, M.H., Free Vibration Analysis of Moderately Thick, Sandwich, Circular Beams. In Proceedings of the World Congress on Engineering (Vol. 2), 2016.

[13] FF Calim Free Vibration Analysis of Timoshenko Beam with Variable Cross-Section. Omer Halisdemir University Journal of Engineering Sciences, 6, 76-82, 2017.

[14] Sankar B.V., An elasticity solution for functionally graded beams. Composites Science and Technology, 61, 689-696. 2001.

[15] Aydogdu, M., Taskin, V., Free vibration analysis of functionally graded beams with simply supported edges. Materials and Design, 28 , 1651-1656, 2007. 
[16] Li X.F., A unified approach for analyzing static and dynamic behaviors of functionally graded Timoshenko and Euler-Bernoulli beams. Journal of Sound and Vibration, 318, 1210-1229, 2008.

[17] Sina S.A., Navazi H.M., Haddadpour H., An analytical method for free vibration analysis of functionally graded beams. Materials and Design, 30, 741-747, 2009.

[18] Şimsek, M., Fundamental frequency analysis of functionally graded beams by using different higherorder beam theories. Nuclear Engineering and Design, 240, 697-705, 2010.

[19] Nuttawit, W., Variddhi, U., Free vibration analysis of functionally graded beams with general elastically end constraints by DTM. World Journal of Mechanics, 2, 297-310, 2012.

[20] Ebrahimia, F., Mokhtaria, M., Semi-analytical vibration characteristics of rotating Timoshenko beams made of functionally graded materials. Latin American Journal of Solids and Structures, 12, 1319$1339,2015$.

[21] Chakraverty, S., Pradhan, KK., Vibration of Functionally Graded Beams and Plates. Academic Press, 2016.

[22] Al Rjoub, Y.S., Hamad, A.G., Free vibration of functionally Euler-Bernoulli and Timoshenko graded porous beams using the transfer matrix method. KSCE. Journal of Civil Engineering, 21, 792-806, 2017.

[23] Rao, S.S., Vibration of continuous systems. John Wiley \& Sons, 2007. 